\title{
PW02-027 - CAPS and cost-effectiveness analysis project
}

\author{
O Della Casa Alberighi ${ }^{1 *}$, L Accame $^{1}$, J Frenkel ${ }^{2}$, M Gattorno ${ }^{3}$, A Martini $^{3}$, B Neven $^{4}$, P Quartier ${ }^{4}$, F Pierotti $^{5}$, \\ G Turchetti $^{5}$
}

From 7th Congress of International Society of Systemic Auto-Inflammatory Diseases (ISSAID)

Lausanne, Switerland. 22-26 May 2013

\section{Introduction}

Ultra-orphan drugs are medicines used to treat exceptionally rare diseases that are chronically debilitating or life-threatening. Low patient numbers make it difficult for pharmaceutical companies to recoup research and development costs, and consequently these medicines are generally very expensive on a per patient basis. European Union (EU) regulations promote the development of orphan drugs; but to contain costs, EU healthcare systems will increasily need the cost-effectiveness analysis (CEA) of therapies when deciding if they should be funded. Conventional methods for CEA of drugs for common conditions do not apply to ultra-orphan drugs; therefore, additional factors need to be considered.

\section{Objectives}

Using the case of ultra-orphan cryopyrin associated periodic syndromes (CAPS) currently investigated by the EuroFever registry, the RaDiCEA (Rare Diseases \& CostEffectiveness Analysis) project is aimed at collecting prospective efficacy, safety, tolerability, treatment adherence (effectiveness data), cost of illness (COI) information, and relative effectiveness of life-long treatment strategies, and at elaborating on CEA modeling in ultra rare diseases.

\section{Methods}

\section{Design and setting}

As a EuroFever registry spin-off, a three-year, international, multicentre, observational, cost-effectiveness study will be conducted in approx. 150 CAPS patients through the Paediatric Rheumatology INternational Trials Organisation (PRINTO) network.

${ }^{1}$ Clinical Pharmacology and Clinical Trial Unit, Giannina Gaslini Institute Pediatric Hospital, Genova, Italy

Full list of author information is available at the end of the article

\section{Participants}

The EuroFever registry project (http://www.printo.it/ eurofever/) involves so far 170 centres of Paediatric Rheumatology and centres of reference for all autoinflammatory diseases in 45 Countries worldwide.

\section{Results}

\section{Main outcome measures}

They will be the retention on treatment and reasons of treatment withdrawal for effectiveness. For safety, the incidence rates of anti-IL-1 agents-emergent adverse events (AEs) and serious AEs will be evaluated in comparison with incidence rates observed in CAPS subjects not exposed to anti-IL-1 agents. The bases for a costeffectiveness model in CAPS will be set by means of a COI evaluation, and of a comparative economic evaluation of different treatment strategies in the National Health Systems'(NHS) perspectives, using CEA of direct health costs (Incremental Cost Effectiveness Ratio ICER), and by measuring quality adjusted life years (QALY), and organ/system damage prevention up to three years.

\section{Expected results}

The RaDiCEA project will assess the long-term effectiveness of different potentially life-long treatment strategies and COI, while exploring the feasibility of a new CEA model to be generated from a rare disease (CAPS) registry.

\section{Conclusion}

As expensive medications like "biologicals" show promising results in some patients with "ultra-orphan" diseases, it becomes more and more important to have detailed information on as many patients as possible. A promising new international collaboration aims to develop a model to evaluate both costs and (long-term) 
benefits in an ultra-orphan group of diseases known as CAPS. The same model may be used in other very rare disorders.

\section{Disclosure of interest}

None declared.

\section{Authors' details}

${ }^{1}$ Clinical Pharmacology and Clinical Trial Unit, Giannina Gaslini Institute Pediatric Hospital, Genova, Italy. ${ }^{2}$ Pediatric Rheumatology, University Medical Center Utrecht, Utrecht, The Netherlands. ${ }^{3}$ 2nd Division of Pediatrics, Giannina Gaslini Institute Pediatric Hospital, Genova, Italy. ${ }^{4}$ Pediatric Immunology, Haematology and Rheumatology Unit, Assistance PubliqueHopitaux de Paris Hopital Necker, Paris, France. ${ }^{5}$ Health Economy, Scuola Superiore S. Anna, Pisa, Italy.

Published: 8 November 2013

doi:10.1186/1546-0096-11-S1-A168

Cite this article as: Alberighi et al:: PW02-027 - CAPS and cost-

effectiveness analysis project. Pediatric Rheumatology 2013 11(Suppl 1):

A168.

Submit your next manuscript to BioMed Central and take full advantage of:

- Convenient online submission

- Thorough peer review

- No space constraints or color figure charges

- Immediate publication on acceptance

- Inclusion in PubMed, CAS, Scopus and Google Scholar

- Research which is freely available for redistribution

Submit your manuscript at www.biomedcentral.com/submit 